\title{
Relationship of milk intake and physical activity to abdominal obesity among adolescents
}

\author{
S. Abreu ${ }^{1}$, R. Santos ${ }^{1,2}$, C. Moreira ${ }^{1}$, P. C. Santos ${ }^{1,3}$, S. Vale ${ }^{1}$, L. Soares-Miranda ${ }^{1}$, \\ R. Autran ${ }^{1}$, J. Mota ${ }^{1}$ and P. Moreira ${ }^{1,4,5}$ \\ ${ }^{1}$ Research Centre in Physical Activity, Health and Leisure, Faculty of Sport, University of Porto, Porto, Portugal; ${ }^{2}$ Maia Institute of \\ Higher Education, Maia, Portugal; ${ }^{3}$ Department of Physical Therapy, School of Health Technology of Porto, Polytechnic Institute \\ of Porto, Vila Nova de Gaia, Portugal; ${ }^{4}$ Faculty of Nutrition and Food Science, University of Porto, Porto, Portugal; ${ }^{5}$ Institute of \\ Public Health, University of Porto, Porto, Portugal
}

Received 16 April 2012; revised 6 November 2012; accepted 7 November 2012

What is already known about this subject

- Diet and physical activity (PA) are recognized as important factors to prevent abdominal obesity (AO).

- Studies have found an inverse relationship between milk intake or milk products and body weight and/or body fat in children and adolescents.

- Evidence suggests that low levels of PA are associated with $\mathrm{AO}$ in youth.
What this study adds

- Our study explored the combined association of milk intake and PA on AO in adolescents, which are most often studied in isolation.

- Our findings suggested that adolescents with high milk intakes, regardless of whether they were active or low active, were less likely to have AO.

- Our findings could have a great epidemiological interest and bring important evidence in the field of $\mathrm{AO}$ management among adolescents.

\section{Summary}

Background: Diet and physical activity (PA) are recognized as important factors to prevent abdominal obesity $(\mathrm{AO})$, which is strongly associated with chronic diseases. Some studies have reported an inverse association between milk consumption and $\mathrm{AO}$.

Objective: This study examined the association between milk intake, PA and AO in adolescents.

Methods: A cross-sectional study was conducted with 1209 adolescents, aged 15-18 from the Azorean Archipelago, Portugal in 2008. AO was defined by a waist circumference at or above the 90th percentile. Adolescent food intake was measured using a semi-quantitative food frequency questionnaire, and milk intake was categorized as 'low milk intake' ( $<2$ servings per day) or 'high milk intake' ( $\geq 2$ servings per day). PA was assessed via a self-report questionnaire, and participants were divided into active ( $>10$ points) and low-active groups ( $\leq 10$ points) on the basis of their reported PA. They were then divided into four smaller groups, according to milk intake and PA: (i) low milk intake/low active; (ii) low milk intake/active; (iii) high milk intake/low active and (iv) high milk intake/active. The association between milk intake, PA and AO was evaluated using logistic regression analysis, and the results were adjusted for demographic, body mass index, pubertal stage and dietary confounders.

Results: In this study, the majority of adolescents consumed semi-skimmed or skimmed milk (92.3\%). The group of adolescents with high level of milk intake and active had a lower proportion of AO than did other groups (low milk intake/low active: 34.2\%; low milk intake/active: 26.9\%; high milk intake/low active: 25.7\%; high milk intake/active: $21.9 \%, P=0.008$ ). After adjusting for confounders, low-active and active adolescents with high levels of milk intake were less likely to have $\mathrm{AO}$, compared with low-active adolescents with low milk intake (high milk intake/low active, odds ratio $[\mathrm{OR}]=0.412,95 \%$ confidence intervals [Cl]: 0.2010.845; high milk intake/active adolescents, $\mathrm{OR}=0.445,95 \% \mathrm{Cl}: 0.235-0.845)$.

Address for correspondence: Sandra Abreu, Centro de Investigação em Actividade Física, Saúde e lazer. Faculdade de Desporto da Universidade do Porto, Rua Dr. Plácido Costa, 91-4200.450 Porto, Portugal. E-mail: sandramrabreu@gmail.com

(C) 2012 The Authors

Pediatric Obesity (C) 2012 International Association for the Study of Obesity. Pediatric Obesity 9, 71-80 
Conclusion: High milk intake seems to have a protective effect on $\mathrm{AO}$, regardless of PA level.

Keywords: Abdominal obesity, adolescents, milk, physical activity.

Abbreviations: $\mathrm{AO}$, abdominal obesity; $\mathrm{PA}$, physical activity; WC, waist circumference; $\mathrm{BMI}$, body mass index; \% BF, percentage of body fat; $\mathrm{FFQ}$, food frequency questionnaire; PAl, physical activity index; $\mathrm{OR}$, odds ratio; $\mathrm{Cl}$, confidence intervals.

\section{Introduction}

In recent decades, the prevalence of obesity, including abdominal obesity (AO), has significantly increased among adolescents (1). These findings are alarming, in view of the fact that $A O$ is an independent risk factor for insulin resistance, hyperinsulinaemia, dyslipidemia and hypertension in youth (2). Despite the upward trend in obesity, there is still a lack of knowledge of the factors associated with $\mathrm{AO}$ in adolescents. It has been reported that diet and physical activity (PA) play an important role in the prevention of $\mathrm{AO}(3,4)$. Several observational and prospective studies have suggested that milk or milk product intake is associated with lower risk of excessive adiposity in children, adolescents and adults $(5-7)$. The weight of evidence suggests that milk intake is more likely to be associated with beneficial weight and body fat than other milk products such as yogurt or cheese (8). It has been suggested that milk is rich in bioactive peptides (whereas other milk products contain little or no such substances) that may modulate body fat accumulation $(9,10)$. On the other hand, other studies have found a positive (11) or null association (12) of milk intake with adiposity.

The emergence of the prevalence of $\mathrm{AO}$ and related conditions parallels with the decreasing levels of PA, and increasing levels of time spent on sedentary activities (television watching, video game playing and computer use) has increased among adolescents $(13,14)$. As recently noted, the practice of structured and vigorous PA is inversely associated with excess central adiposity (3). Despite the overwhelming evidence of the association between PA and body composition, PA levels are also linked to other health-related factors, lifestyle patterns and psychosocial well-being (15).

Although evidences suggest that milk intake and PA have an independent role in $\mathrm{AO}$, gaps remain in the literature on the combined effects. Moreover, these two lifestyle habits are not mutually exclusive and often co-exist in the same individual (16). In a recent review, it is suggested that more research is needed in order to compare the combined effects of milk products consumption and PA on body composition (17). To the best of our knowledge, no study has examined this combined association in adoles- cents. In this context, the aim of this study was to identify the association of milk intake and PA on AO in a sample of Portuguese adolescents.

\section{Materials and methods}

\section{Sampling}

Data for the present cross-sectional study were derived from a school-based study - The Azorean Physical Activity and Health Study II - which aimed to evaluate PA, physical fitness, overweight/obesity prevalence, dietary intake, health-related quality of life and other factors in 15-18-year-old adolescents in 2008. This study was carried out in six of the nine Azorean Islands (S. Miguel, Terceira, Faial, Pico, S. Jorge and Graciosa), where 95\% of the Azorean population lives.

All participants in this study were informed of its goals, and the parent or guardian of each participant provided written informed consent for his/her child to participate. The study was approved by the Faculty of Sport, University of Porto, and the Portuguese Foundation for Science and Technology Ethics Committee; it was conducted in accordance with the World Medical Association's Helsinki Declaration for Human Studies.

The population was selected by means of proportionate stratified random sampling, taking into account the location (island) and number of students, by age and sex, in each school. The estimated number of subjects for the representativeness of adolescent population was 1422, but in order to prevent incomplete information, data were collected from 1515 adolescents. Some adolescents were not included in our analysis $(n=306)$, because information was missing on their dietary intake $(n=286)$ and waist circumference (WC; $n=20$ ). This resulted in the collection of data for a total of 1209 participants (503 boys). The subjects who were excluded from this study did not significantly differ from those who were included, with regard to age (16.2 \pm 1.0 years vs. $16.1 \pm 1.0$ years, $P=0.158$ ), parental education $(9.1 \pm 4.5$ years vs. $9.1 \pm 4.4$ years, $P=0.890)$ and gender (girls: $61.1 \%$ vs. $58.4 \%$ and boys: $38.9 \%$ vs. $41.6 \%, P=0.388$ ). Finally, the sample was weighted in accordance with the distribution of the Azorean 
population in schools and so as to guarantee the real representativeness of each group (by age and gender).

\section{Anthropometric measures Body height and body weight}

Body height and body weight were determined using standard anthropometric methods. Height was measured to the nearest millimetre in bare or stocking feet, with adolescents standing upright against a Holtain portable stadiometer (Crymych, Pembrokeshire, UK). Weight was measured to the nearest $0.10 \mathrm{~kg}$, with participants lightly dressed (underwear and T-shirt) and with the use of a portable digital beam scale (Tanita Inner Scan BC 532, Tanita, Tokyo, Japan).

Body mass index (BMI) was calculated using the ratio of weight/height ${ }^{2}\left(\mathrm{~kg} \mathrm{~m}^{-2}\right)$. Subjects were classified as normal weight, overweight or obese, according to age- and sex-specific cut-off points specified by the International Obesity Task Force $(18,19)$. Underweight subjects $(2.6 \%)$ were combined with subjects in the normal-weight category because of the fact that they represented a small proportion of the sample. Percentage of body fat (\% BF) was assessed using bioelectric impedance analysis (Tanita Inner Scan BC 532).

\section{Waist circumference}

WC measurements were taken midway between the 10th rib and the iliac crest and recorded to $0.1 \mathrm{~cm}$. A non-elastic flexible tape measure was used, with subjects standing erect - arms by sides, feet together and abdomen relaxed - as well as without clothing covering the waist area. Subjects were divided into two categories ( $<90$ th and $\geq 90$ th percentiles), according to age- and sex-specific cut-off points specified by Sardinha et al. (20). Subjects who were in the 90th percentile or above were considered to have $A O(21)$.

\section{Pubertal stage}

To determine pubertal stage (which ranged from 1 to 5), each subject was asked to self-assess his/her stage of development of secondary sex characteristics. Breast development in girls and genital development in boys was evaluated according to criteria outlined by Tanner and Whitehouse (22). Adolescents in Tanner stage $1(0.4 \%)$ were combined with subjects in the Tanner stage 2 because of the fact that they represented a small proportion of the sample.

\section{Socio-demographic and lifestyle variables}

Participants answered a questionnaire that assessed several socio-demographic and lifestyle variables.

\section{Smoking}

Participants were classified as non-smokers, former smokers (individuals who had stopped smoking for at least 6 months), occasional smokers (individuals who smoked, on average, less than one cigarette per day) and current smokers (individuals who smoked at least one cigarette per day) (23). Occasional smokers were recoded and combined with current smokers because of the fact that they represented a small proportion of the sample.

\section{Parental education}

For the present study, highest level of parental education (measured by number of school years completed) was used as a proxy measure of socioeconomic status. Participants were divided into three categories, reflecting divisions within the Portuguese educational system: mandatory or less ( $\leq 9$ school years), secondary (10-12 school years) and college/university (>12 school years).

\section{Dietary intake}

Dietary intake was measured via a self-administered semi-quantitative food frequency questionnaire (FFQ), validated for the Portuguese adults (24). This semi-quantitative FFQ was designed in accordance with criteria laid out by Willett (25) and adapted to include a variety of typical Portuguese food items. The FFQ was adapted for adolescents by including foods more frequently eaten by this age group (26); the adolescent version covered the previous 12 months and comprised 91 food items or beverage categories. For each item, the questionnaire offered nine frequency response options, ranging from 'never' to 'six or more times per day', and standard portion size and seasonality. Any foods not listed in the questionnaire could be listed by participants in a free-response section. Energy and nutritional intake were estimated with regard to respondents' ratings of the frequency, portion and seasonality of each item, using the software Food Processor Plus (ESHA Research Inc., Salem, OR, USA). This programme uses nutritional information from the United States that has been adapted for use with typical Portuguese foods and beverages. In order to verify the inter-item consistency, the Cronbach's alpha test was applied to the dimensions of 
the FFQ and the score obtained $(\alpha=0.892)$ was high, which indicated a good internal consistency.

The amount of milk (whole, semi-skimmed and skimmed) that counted as a single serving was considered to be $250 \mathrm{~mL}$. We included all types of milk in one variable because the majority of adolescents were consuming semi-skimmed (83.7\%) or skimmed milk (8.6\%). Participants were categorized according to the new Portuguese Food Wheel guide (27) and adolescents who consumed two or more servings of milk per day were included in the 'high milk intake group', while those who consumed less than two servings per day comprised the 'low milk intake group'.

\section{Physical activity}

PA was assessed via a self-report questionnaire that evaluated leisure-time PAs (28). This questionnaire has been shown to have good test-retest reliability among Portuguese adolescents (intraclass correlation coefficient: 0.92-0.96) (29). It consists of five questions with four answer choices (each rated on a 4-point scale): (i) outside school, do you take part in organized sports/PAs?; (ii) outside school, do you take part in non-organized sports/PAs?; (iii) outside school hours, how many times a week do you take part in sports or PAs for at least 20 min?; (iv) outside school hours, how many hours a week do you usually take part in PAs, so much that you get out of breath or sweat?; and (v) do you take part in competitive sports? The maximum number of points possible was 20. A PA index (PAI) was obtained for each respondent by totalling his/her points, which corresponded to activity level rankings that ranged from 'sedentary' to 'vigorous'. Participants whose PAls were greater than 10 points were classified as 'active', while those whose PAls were 10 points or less were classified as 'low active' (29); this procedure has been validated (30).

\section{Statistical analysis}

For the purposes of this study, participants were divided into four groups, according to their milk intake (high or low) and PA (active or low active): (i) low milk intake/low active; (ii) low milk intake/active; (iii) high milk intake/low active and (iv) high milk intake/active.

The Kolmogorov-Smirnov test was used to assess the assumption of normality. One-way analysis of variance, with the Bonferroni post hoc test, was performed to compare continuous variables, and the chi-square test was used to test for categorical vari- ables across groups. When the continuous variables were found to not be normally distributed, the Kruskal-Wallis test was used to determine differences between groups, and the Mann-Whitney test was used to examine unique pairs. In this report, descriptive analysis is presented in terms of means and standard deviations, unless otherwise stated.

A multivariate logistic regression model was constructed to verify the relationship between $A O$ and the combined associations of milk intake and PA, adjusting for age (in years), gender (reference boys), parental education (reference - mandatory or less), BMI (reference - obese), pubertal stage, energy intake (in kcal), total calcium intake (in $\mathrm{mg}$ ), protein intake $\left(\mathrm{g} \mathrm{kg}^{-1}\right)$, total fat intake (\% of energy) and dietary fiber (in $\mathrm{g} 1000 \mathrm{kcal}^{-1}$ ). Age and dietary variables were entered as continuous variables. Furthermore, we adjusted the logistical model by underreporting energy intake, which was estimated using the ratio between reported energy intake and predicted basal metabolic rate $(31,32)$. The thresholds that defined low-energy reporters (under-reporters) were 1.70 and 1.71 for girls and boys between 15 and 17 years old, and 1.67 and 1.81 for girls and boys aged 18. 'Low-energy reporter' (a categorical variable) was included in the model as a confounding factor.

Odds ratios (OR) and 95\% confidence intervals $(\mathrm{Cl})$ were computed across groups, with the 'low milk intake/low-active' group as the reference group. A $P$-value of $<0.05$ was regarded as significant. All analyses were performed using PASW Statistics V.18 (SPSS, Chicago, IL, USA).

\section{Results}

Descriptive characteristics of the adolescents in the sample are shown in Table 1. The higher proportion of girls was seen in the low-activity groups, regardless of milk intake $(P<0.001)$. Adolescents in the high milk intake/active group had higher body weight compared with adolescents in the high milk intake/ low-active group (61.4 [14.4] vs. 58.6 [14.6], $P=0.001$, respectively), and higher body height and lower \% BF compared with adolescents in the high milk intake/low active and in the low milk intake/lowactive groups $(P<0.001$, for all). Active adolescents had lower \% BF compared with low-active adolescents, regardless of milk intake $(P<0.001$, for all). The higher proportion of parents with mandatory or less education was seen in the low milk intake/lowactive group $(P<0.001)$. No significant differences were seen in age, BMI, pubertal stage and smoking across groups. 


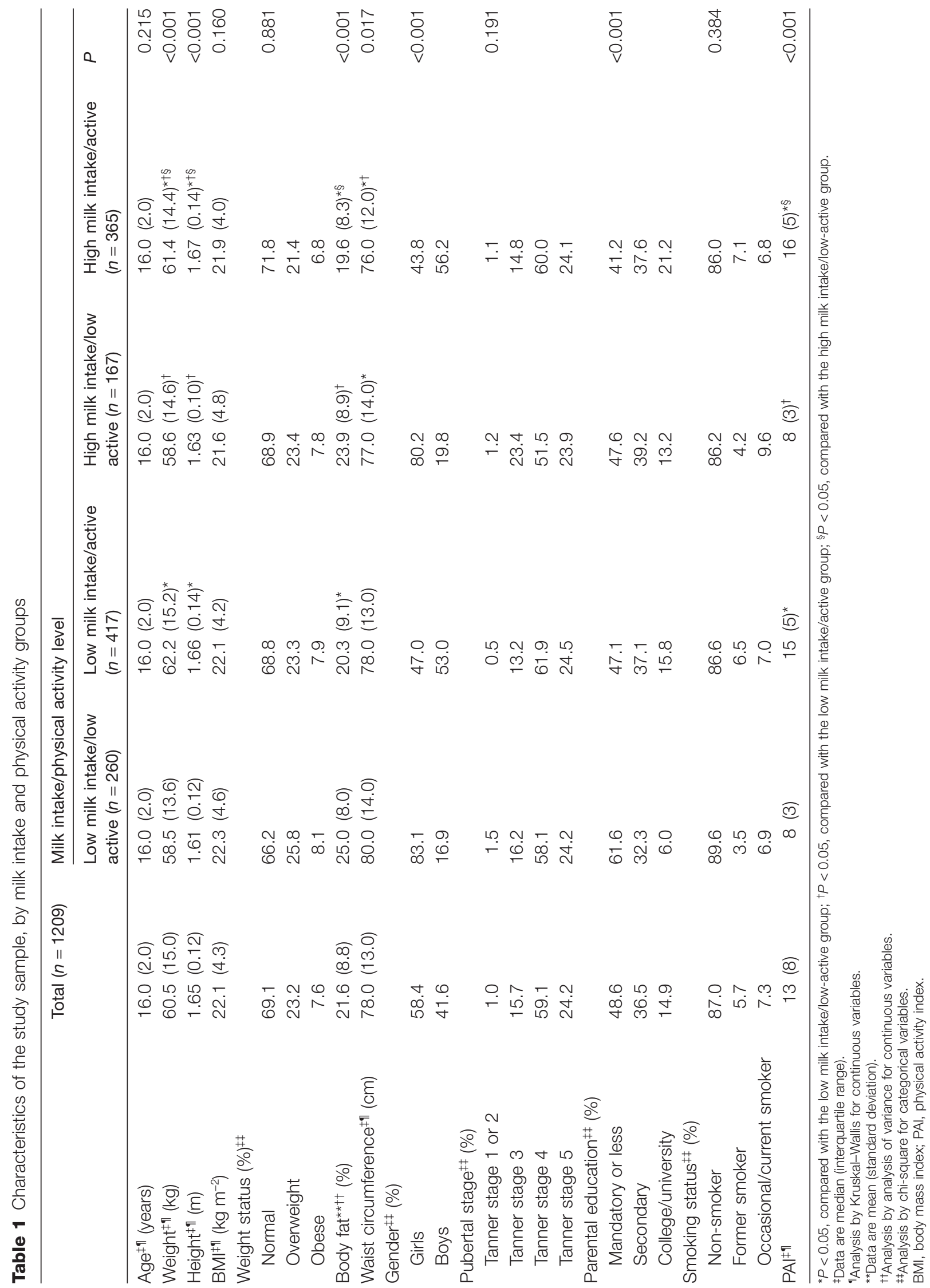


Adolescents with high milk intakes had lower proportions of $A O$, compared with those who had low milk intakes $(23.1 \%$ vs. $29.7 \%, P=0.006$, respectively). Active adolescents also had lower proportions of $\mathrm{AO}$ than low-active adolescents $(24.6 \%$ vs. $30.9 \%, P=0.011$, respectively).

The energy intakes and dietary characteristics of each group are presented in Table 2. Regardless of whether they were active or low active, adolescents whose milk intakes were high had higher levels of energy and total calcium and protein intake, compared with those who had low milk intake $(P<0.05)$. There was no significant difference across groups with regard to carbohydrate and total fat intake.

The proportion of $\mathrm{AO}$ across milk intake and PA groups, as indicated in Fig. 1, showed that adolescents with high levels of milk intake and activity had lower proportions of $\mathrm{AO}$, compared with other groups (low milk intake/low active: $34.2 \%$, vs. low milk intake/active: $26.9 \%$, vs. high milk intake/low active: $25.7 \%$, vs. high milk intake/active: $21.9 \%$, $P=0.008)$.

The results of the multivariate logistic regression analysis, predicting $\mathrm{AO}$ from a combination of milk intake and PA, are shown in Table 3. After adjusting for demographic and dietary variables, low-active and active adolescents with high milk intakes were less likely to have $\mathrm{AO}$ than were low-active adolescents with low milk intakes (low milk intake/low active, $\mathrm{OR}=0.928,95 \% \mathrm{Cl}$ : 0.562-1.531; high milk intake/low active, $\mathrm{OR}=0.412,95 \% \mathrm{Cl}$ : $0.201-$ 0.845; high milk intake/active, $\mathrm{OR}=0.445,95 \% \mathrm{Cl}$ : $0.235-0.845)$. To demonstrate whether it is really milk intake making the difference, we made an additional multivariate logistic regression analysis with low milk intake/active group as the reference group. Low-active and active adolescents with high levels of milk intake remain to be less likely to have $\mathrm{AO}$ even after compared with active adolescents with low milk intake (low milk intake/low active, $\mathrm{OR}=1.078,95 \%$ Cl: 0.653-1.779; high milk intake/low active, $\mathrm{OR}=0.444,95 \% \mathrm{Cl}: 0.217-0.909$; high milk intake/ active adolescents, OR $=0.480,95 \% \mathrm{Cl}$ : 0.2630.876).

\section{Discussion}

The present study explored the combined association of milk intake and PA on AO in adolescents. The results suggested that adolescents with high milk intakes, regardless of whether they were active or low active, were less likely to have $\mathrm{AO}$, compared with those who had low milk intakes. This association was not confounded by other lifestyle factors or

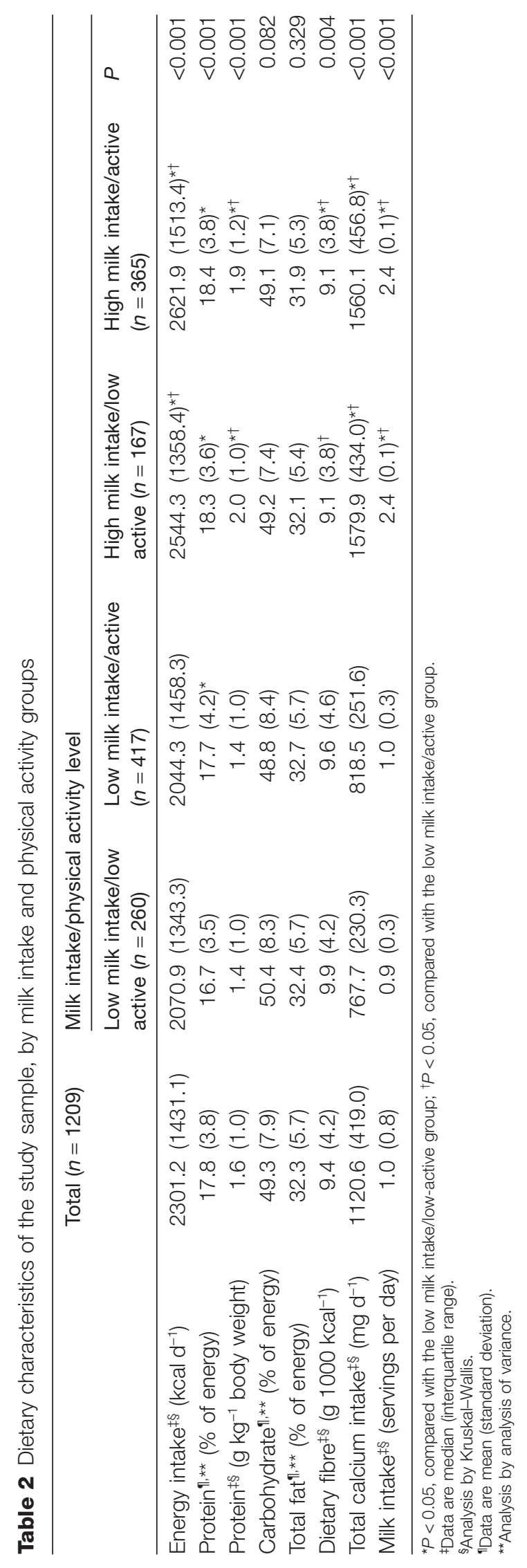




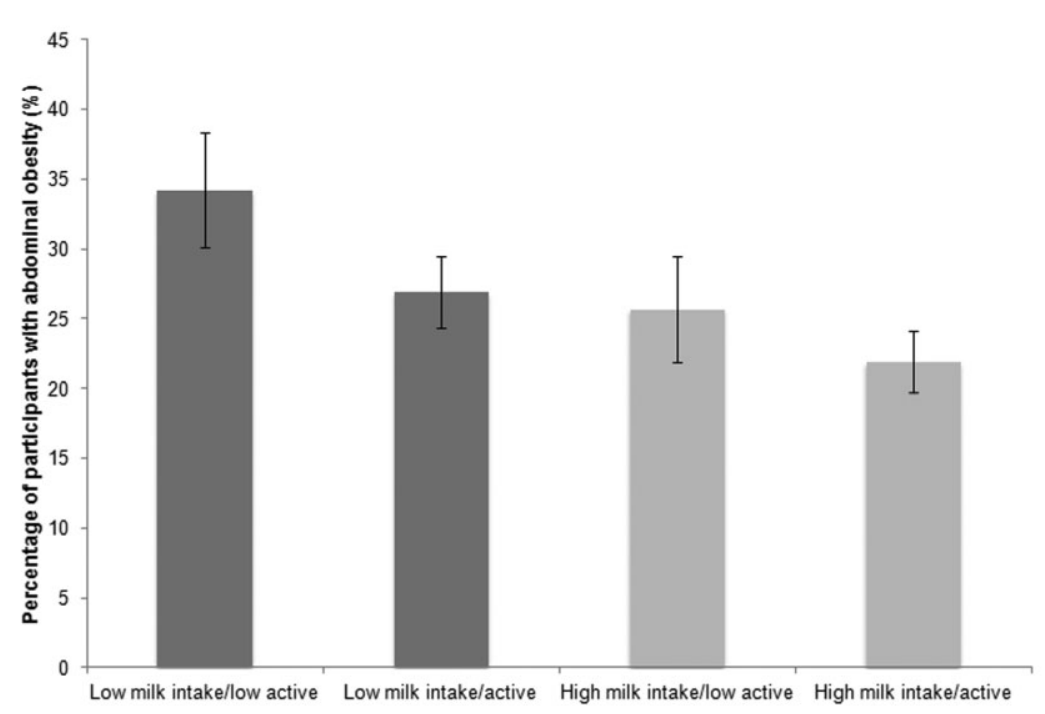

Figure 1 Proportion of subjects with abdominal obesity across milk intake and physical activity groups.

\begin{tabular}{|c|c|c|c|c|c|c|c|}
\hline & & \multicolumn{3}{|c|}{ Model 1} & \multicolumn{3}{|c|}{ Model 2} \\
\hline & & OR & $95 \% \mathrm{Cl}$ & $P^{*}$ & OR & $95 \% \mathrm{Cl}$ & $P^{*}$ \\
\hline \multirow[t]{2}{*}{ Low milk intake } & Low active & 1 & Reference & 0.008 & 1 & Reference & 0.027 \\
\hline & Active & 0.706 & $0.501-0.987$ & & 0.928 & $0.562-1.531$ & \\
\hline \multirow[t]{2}{*}{ High milk intake } & Low active & 0.666 & $0.433-1.025$ & & 0.412 & $0.201-0.845$ & \\
\hline & Active & 0.539 & $0.378-0.770$ & & 0.445 & $0.235-0.845$ & \\
\hline
\end{tabular}

Table 3 Odds ratio for abdominal obesity by milk intake and physical activity groups

Model 1 - unadjusted model. Model 2 - adjusted for age (years), gender (reference - boys), parental education (reference - mandatory or less), body mass index (reference - obese), pubertal stage, low-energy reporter, energy intake (kcal), total fat intake (\% of energy), total calcium intake (mg), protein intake $\left(\mathrm{g} \mathrm{kg}^{-1}\right.$ body weight) and density fibre (g $\left.1000 \mathrm{kcal}{ }^{-1}\right)$.

1, reference category; $\mathrm{Cl}$, confidence interval, OR, odds ratio.

nutritional variables, as it remained significant after adjustments.

Most cross-sectional and prospective studies have found an inverse relationship between milk intake or milk products and BMI, body weight and/or body fat in children and adolescents $(5,7,33)$. Furthermore, evidence shows that the consumption of milk and milk products does not negatively affect weight and body composition (34). However, studies examining the association between milk intake or milk products and $\mathrm{AO}$ are limited. In one study with children, increased milk consumption was associated with lower WC (35). Bradlee et al. (36) analyzed data from the Third National Health and Nutrition Examination Survey and also found that mean dairy intake was inversely associated with central obesity in adolescents. Previous results, derived from the same sample, had shown that dairy product intake had a protective association with $\mathrm{AO}$ in boys (37). A randomized controlled trial on the effects of a dairy-rich diet on $\mathrm{AO}$ with obese children showed that those

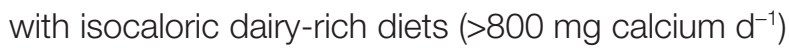
had lower WC than other groups (i.e. controls with and without energy restrictions) at the end of the study (38). It is noteworthy that, in addition to its possible 'anti-obesity' effect, milk is an excellent source of nutrients (such as calcium) for adolescents, who experience a period characterized by dynamic changes that occur in response to growth and puberty. Hence, consumption of recommended amounts of milk may help adolescents meet their nutrient requirements and improve their diets' quality $(34,39)$. Moreover, moderate evidence shows that intake of milk and milks products is linked to improved bone health in children and adolescents and is also associated with reduced risk of cardiovascular disease, type 2 diabetes and blood pressure in adults (40).

In this study, we also found that active adolescents had a lower proportion of AO. PA also protects against central adiposity by increasing immediate energy requirements, which causes important changes in fuel utilization and mobilization (41). Evidence suggests that low levels of leisure-time PA are associated with $\mathrm{AO}$ in youth (3). Klein-Platat et al. (42) reported that, in an adoles- 
cent sample, AO was negatively associated with structured PA (outside school, >140 min week ${ }^{-1}$ ) and positively associated with sedentary activities (e.g. television, watching). By the same token, Ortega et al. (43) found that children and adolescents in the lowest tertile of vigorous PA had higher odds of having high WC, when compared with those in the highest tertile.

Concerning dietary habits and PA levels, some studies have found that the consumption of food by more active and less active adolescents differs $(16,44)$. In a study by Ottevaere et al. (16), the most active adolescents consumed more milk products than did their less active counterparts. However, previous research indicates that spending more time on PA does not exclusively result in healthier eating habits $(16,44)$. Although, in our study, the majority of active adolescents showed low milk intake, active adolescents with high milk intake, when compared with other groups, had lower proportions of $A O$, which shows the relevance of exploring both dietary patterns and PA simultaneously when assessing $A O$ in adolescents.

When interpreting the results of the combined association between milk intake and PA, we observed that adolescents with high milk intake showed lower odds of expressing $A O$, regardless of their PA levels. These results are further enhanced by the lack of significance between groups with low milk intake where there was no significant differences between be active or low active. Thus, this finding suggests that the consumption of milk may overcome the potentially negative effects of low PA levels on the likelihood of having $\mathrm{AO}$. Furthermore, milk compounds may also be involved in body fat distribution. Visceral adipose tissue has greater amounts of 11- $\beta$-hidroxysteroid dehydrogenase type 1 (45), which is over-expressed in vitro in those with central adiposity (46). It has been suggested that a highcalcium and high-dairy diet down-regulates 11- $\beta$ hidroxysteroid dehydrogenase type 1 expression and decreases the concentration of glucocorticoid, which consequently decreases the size of adipose fat deposits (45). However, we cannot exclude the hypothesis that milk consumption may also be associated with other healthy eating habits and healthier lifestyles, which may protect against $\mathrm{AO}$.

In addition, we found that adolescents with higher milk intake and activity levels were taller and heavier but had lower \% BF than adolescents who were less active and had higher high milk intake. It is well established that increased PA is associated with lower fatness (47) and thus the combined effect of PA and milk intake may enhance beneficial total body fat outcomes. Moreover, milk consumption and PA, along with other factors (i.e. genetics, age, gender, endocrine balance and overall diet) may influence growth. It has been described that children who do not drink milk have a shorter stature than those who do consume milk regularly $(48,49)$. On the other hand, PA (i.e. sport participation) has been associated with bone accretion showing an important osteogenic effect, mainly when high-impact and weight-bearing PA occurs $(50,51)$.

We also found that although energy intake is higher in adolescents with high milk consumption, the additional energy intake does not result in higher odds of AO. In a study to determine the effects of a calciumrich diet on weight gain during 2 years, 9-year-old girls were randomly assigned to supplying at least $1500 \mathrm{mg}$ (primarily from dairy food) of calcium $\mathrm{d}^{-1}$ or their usual diet (52). Although girls in the calcium-rich diet group consumed approximately 150 more calories $\mathrm{d}^{-1}$, they did not have greater increases in body weight, BMI or fat or lean mass compared with the usual diet group. Furthermore, girls who consumed calcium-rich diet also significantly increased their intake of essential nutrients including calcium, protein, vitamins $A$ and $D$, phosphorus and magnesium compared with girls on their usual diets. In adults, Zemel et al. (53) conducted 9-month randomized trials to compare the effects of low- $\quad<1$ serving per day) and high-dairy diet ( $>3$ servings per day) on weight maintenance. Although the results showed that the high-dairy diet group had a higher energy intake than the low-dairy group, there were no differences in weight and body composition between the two groups after the intervention. Thus, the author suggested that the high-dairy diet group exhibited evidence of greater fat oxidation and was able to consume greater energy without greater weight gain compared with the low-dairy group.

Some limitations to our study should be addressed. First, it should be noted that, as in other cross-sectional studies, conclusions related to cause and effect cannot be drawn. Second, the measure of AO used in this study is an indirect estimate of abdominal fat and there are some sophisticated methods to accurately measure abdominal fat, such as magnetic resonance imagining or dual-energy X-ray absorptiometry. However, such techniques are not feasible to apply in large epidemiological studies because they are complex, time consuming and expensive. Furthermore, it has been suggested that WC is one of the most common proxy measures of $A O$ (1) and is strongly associated with visceral adipose tissue (54). Third, because in our sample the majority of adolescents (92.7\%) consumed 
semi-skimmed and skimmed milk, we cannot state that any kind of milk is protective against AO. Moreover, we did not include in our analysis all milk products. However, the analysis with total milk product intake (i.e. milk, cheese and yogurt) was done but no significant association was found with $\mathrm{AO}$. The lack of association between total dairy product and $A O$ may be due to the nutritional differences between yogurt, cheese and milk. Cheese is characterized by its fat content and yogurt has frequently more sugar (added in industrial process) than other milk product. Finally, with the use of self-reported PA and dietary intake data, one cannot rule out some reporting bias. Yet, both questionnaires have been previously tested $(24,29)$, and analysis was controlled to prevent the misreporting of energy intake.

In conclusion, we found that high milk intake seems to have a protective effect on $\mathrm{AO}$, regardless of PA levels in adolescents. Future prospective and randomized clinical investigations, with more accurate measures, are needed on the combined effects of milk intake and/or milk products and PA on AO.

\section{Conflict of Interest Statement}

The authors declare no conflict of interest.

\section{Acknowledgements}

This study was supported by FCT-MCTES Grants nos: BPD/65180/2009, BD/44422/2008, BD/36796/2007, SFRH/BPD/76947/2011 and PTDC/DES/098309/2008, and by the Azorean Government.

\section{References}

1. Li C, Ford ES, Mokdad AH, Cook S. Recent trends in waist circumference and waist-height ratio among US children and adolescents. Pediatrics 2006; 118: e1390e1398.

2. Bacha F, Saad R, Gungor N, Janosky J, Arslanian SA. Obesity, regional fat distribution, and syndrome $X$ in obese black versus white adolescents: race differential in diabetogenic and atherogenic risk factors. J Clin Endocrinol Metab 2003; 88: 2534-2540.

3. Kim Y, Lee S. Physical activity and abdominal obesity in youth. Appl Physiol Nutr Metab 2009; 34: 571-581.

4. Suliga E. Visceral adipose tissue in children and adolescents: a review. Nutr Res Rev 2009; 22: 137-147.

5. Barba G, Troiano E, Russo P, Venezia A, Siani A. Inverse association between body mass and frequency of milk consumption in children. Br J Nutr 2005; 93: 15-19. 6. Marques-Vidal P, Goncalves A, Dias CM. Milk intake is inversely related to obesity in men and in young women: data from the Portuguese Health Interview Survey 19981999. Int J Obes (Lond) 2006; 30: 88-93.

7. Novotny R, Acharya S, Grove JS, Daida YG, Vogt TM. Higher dairy intake is associated with lower body fat during adolescence. FASEB J 2003; 18: A2277. [Abstract].

8. Louie JC, Flood VM, Hector DJ, Rangan AM, Gill TP. Dairy consumption and overweight and obesity: a systematic review of prospective cohort studies. Obes Rev 2011; 12: e582-e592.

9. Shah NP. Effects of milk-derived bioactives: an overview. Br J Nutr 2000; 84(Suppl. 1): S3-S10.

10. Zemel MB. Role of dietary calcium and dairy products in modulating adiposity. Lipids 2003; 38: 139-146.

11. Berkey CS, Rockett HR, Willett WC, Colditz GA. Milk, dairy fat, dietary calcium, and weight gain: a longitudinal study of adolescents. Arch Pediatr Adolesc Med 2005; 159: 543-550.

12. Noel SE, Ness AR, Northstone K, Emmett P, Newby PK. Milk intakes are not associated with percent body fat in children from ages 10 to 13 years. J Nutr 2011; 141: 2035-2041.

13. Eaton DK, Kann L, Kinchen S, et al. Youth risk behavior surveillance - United States, 2009. MMWR Surveill Summ 2010; 59: 1-142.

14. Pate RR, Mitchell JA, Byun W, Dowda M. Sedentary behaviour in youth. Br J Sports Med 2011; 45: 906-913. 15. World Health Organization. Global Recommendations on Physical Activity for Health. World Health Organization: Geneva, 2010.

16. Ottevaere C, Huybrechts I, Beghin L, et al. Relationship between self-reported dietary intake and physical activity levels among adolescents: the HELENA study. Int J Behav Nutr Phys Act 2011; 8: 8.

17. Dougkas A, Reynolds CK, Givens ID, Elwood PC, Minihane AM. Associations between dairy consumption and body weight: a review of the evidence and underlying mechanisms. Nutr Res Rev 2011; 15: 1-24.

18. Cole TJ, Bellizzi MC, Flegal KM, Dietz WH. Establishing a standard definition for child overweight and obesity worldwide: international survey. BMJ 2000; 320: 12401243.

19. Cole TJ, Flegal KM, Nicholls D, Jackson AA. Body mass index cut offs to define thinness in children and adolescents: international survey. BMJ 2007; 335: 194. 20. Sardinha LB, Santos R, Vale S, et al. Waist circumference percentiles for Portuguese children and adolescents aged 10 to 18 years. Eur J Pediatr 2011; 171: 499-505. 21. Zimmet P, Alberti KG, Kaufman F, et al. The metabolic syndrome in children and adolescents - an IDF consensus report. Pediatr Diabetes 2007; 8: 299-306.

22. Tanner JM, Whitehouse $\mathrm{RH}$. Clinical Iongitudinal standards for height, weight, height velocity, weight velocity, and stages of puberty. Arch Dis Child 1976; 51: 170179.

23. World Health Organization. Guidelines for Controlling and Monitoring the Tobacco Epidemic. WHO: Geneva, 1998.

24. Ramos E. Health Determinants in Porto Adolescents The Epiteen Cohort. University of Porto: Porto, 2006. 
25. Willett W. Food Frequency Methods Nutritional Epidemiology, 2nd edn. Oxford University Press: New York, 1998, 74-100.

26. Silva D, Rego C, Guerra A. Characterization of food habits and comparative study between two methods of food assessment in adolescents. Rev Aliment Humana 2004; 10: 33-40.

27. Rodrigues SS, Franchini B, Graca P, de Almeida MD. A new food guide for the Portuguese population: development and technical considerations. J Nutr Educ Behav 2006; 38: 189-195.

28. Telama R, Yang X, Laakso L, Viikari J. Physical activity in childhood and adolescence as predictor of physical activity in young adulthood. Am J Prev Med 1997; 13: 317-323.

29. Mota J, Esculcas C. Leisure-time physical activity behavior: structured and unstructured choices according to sex, age, and level of physical activity. Int J Behav Med 2002; 9: 111-121.

30. Raitakari OT, Porkka KV, Taimela S, Telama R, Rasanen L, Viikari JS. Effects of persistent physical activity and inactivity on coronary risk factors in children and young adults. The Cardiovascular Risk in Young Finns Study. Am J Epidemiol 1994; 140: 195-205.

31. Goldberg GR, Black AE, Jebb SA, et al. Critical evaluation of energy intake data using fundamental principles of energy physiology: 1. Derivation of cut-off limits to identify under-recording. Eur J Clin Nutr 1991; 45: 569-581.

32. Black AE. Critical evaluation of energy intake using the Goldberg cut-off for energy intake:basal metabolic rate. A practical guide to its calculation, use and limitations. Int $J$ Obes Relat Metab Disord 2000; 24: 1119-1130.

33. Novotny R, Daida YG, Acharya S, Grove JS, Vogt TM. Dairy intake is associated with lower body fat and soda intake with greater weight in adolescent girls. J Nutr 2004; 134: 1905-1909.

34. Spence LA, Cifelli CJ, Miller GD. The role of dairy products in healthy weight and body composition in children and adolescents. Curr Nutr Food Sci. 2011; 7: 40-49. 35. Hirschler V, Oestreicher K, Beccaria M, Hidalgo M, Maccallini $G$. Inverse association between insulin resistance and frequency of milk consumption in low-income Argentinean school children. J Pediatr 2009; 154: 101105.

36. Bradlee ML, Singer MR, Qureshi MM, Moore LL. Food group intake and central obesity among children and adolescents in the Third National Health and Nutrition Examination Survey (NHANES III). Public Health Nutr 2010; 13: 797-805.

37. Abreu S, Santos R, Moreira C, et al. Association between dairy product intake and abdominal obesity in Azorean adolescents. Eur J Clin Nutr 2012; 66: 830-835. 38. Kelishadi R, Zemel MB, Hashemipour M, Hosseini M, Mohammadifard N, Poursafa P. Can a dairy-rich diet be effective in long-term weight control of young children? J Am Coll Nutr 2009; 28: 601-610.

39. Marshall TA, Eichenberger Gilmore JM, Broffitt B, Stumbo PJ, Levy SM. Diet quality in young children is influenced by beverage consumption. I Am Coll Nutr 2005; 24: 65-75.

40. U.S. Department of Agriculture, U.S. Department of Health and Human Services. Dietary Guidelines for Americans, 2010. US Government Printing Office: Washington, DC, 2010.

41. Samaras K, Campbell LV. The non-genetic determinants of central adiposity. Int J Obes Relat Metab Disord 1997; 21: 839-845.

42. Klein-Platat C, Oujaa M, Wagner A, et al. Physical activity is inversely related to waist circumference in 12-y-old French adolescents. Int J Obes (Lond) 2005; 29: $9-14$.

43. Ortega FB, Ruiz JR, Sjostrom M. Physical activity, overweight and central adiposity in Swedish children and adolescents: the European Youth Heart Study. Int J Behav Nutr Phys Act 2007; 4: 61.

44. Cavadini C, Decarli B, Grin J, Narring F, Michaud PA. Food habits and sport activity during adolescence: differences between athletic and non-athletic teenagers in Switzerland. Eur J Clin Nutr 2000; 54(Suppl 1):S16S20.

45. Morris KL, Zemel MB. 1,25-dihydroxyvitamin D3 modulation of adipocyte glucocorticoid function. Obes Res 2005; 13: 670-677.

46. Masuzaki $H$, Paterson J, Shinyama $H$, et al. A transgenic model of visceral obesity and the metabolic syndrome. Science 2001; 294: 2166-2170.

47. Must A, Tybor DJ. Physical activity and sedentary behavior: a review of longitudinal studies of weight and adiposity in youth. Int J Obes (Lond) 2005; 29(Suppl. 2): S84-S96.

48. Black RE, Williams SM, Jones IE, Goulding A. Children who avoid drinking cow milk have low dietary calcium intakes and poor bone health. Am J Clin Nutr 2002; 76: 675-680.

49. Stallings VA, Oddleifson NW, Negrini BY, Zemel BS, Wellens R. Bone mineral content and dietary calcium intake in children prescribed a low-lactose diet. J Pediatr Gastroenterol Nutr 1994; 18: 440-445.

50. Vicente-Rodriguez G. How does exercise affect bone development during growth? Sports Med 2006; 36: 561569.

51. Gracia-Marco L, Moreno LA, Ortega FB, et al. Levels of physical activity that predict optimal bone mass in adolescents: the HELENA study. Am J Prev Med 2011; 40: 599-607.

52. Lappe JM, Rafferty KA, Davies KM, Lypaczewski G. Girls on a high-calcium diet gain weight at the same rate as girls on a normal diet: a pilot study. J Am Diet Assoc 2004; 104: 1361-1367.

53. Zemel MB, Donnelly JE, Smith BK, et al. Effects of dairy intake on weight maintenance. Nutr Metab (Lond) 2008; 5: 28.

54. de Koning L, Merchant AT, Pogue J, Anand SS. Waist circumference and waist-to-hip ratio as predictors of cardiovascular events: meta-regression analysis of prospective studies. Eur Heart J 2007; 28: 850-856. 